This item was submitted to Loughborough's Research Repository by the author.

Items in Figshare are protected by copyright, with all rights reserved, unless otherwise indicated.

Meeting frequency response requirements with uncertain system inertia - A UK perspective

PLEASE CITE THE PUBLISHED VERSION

http://dx.doi.org/10.1109/ICRERA.2016.7884393

PUBLISHER

(c) IEEE

VERSION

AM (Accepted Manuscript)

LICENCE

CC BY-NC-ND 4.0

REPOSITORY RECORD

Forkasiewicz, K., M. Coldwell, Andrew M. Cross, and Dani Strickland. 2019. "Meeting Frequency Response Requirements with Uncertain System Inertia - A UK Perspective”. figshare. https://hdl.handle.net/2134/24984. 


\section{Meeting Frequency Response Requirements with Uncertain System Inertia - a UK perspective}

\author{
K Forkasiewicz, M Coldwell, \\ National Grid \\ St Catherine's Lodge, Bearwood Rd \\ Wokingham, UK \\ Kane.Forkasiewicz@nationalgrid.com
}

\author{
A Cross, D Strickland, \\ Energy and Applied Science \\ Aston University \\ Birmingham, UK \\ d.strickland@aston.ac.uk
}

\begin{abstract}
National Grid has a statutory obligation to manage the frequency between pre-defined limits. If there isn't effective frequency response available then the likelihood of a frequency excursion outside of statutory limits will increase. To this end, National Grid are going to trial enhanced frequency response as a mechanism to assist with frequency control in the light of reducing system inertia. This paper models rapid response as a function of system inertia and proposes that either primary response needs to ramp up more quickly in order to remain effective at low system inertia levels or a faster response time is needed. It has been determined that both these methods are more effective than just increasing the generation held in reserve for frequency response. The outcome of this research supports the growing body of evidence in literature for the procurement of rapid response subject to further research and testing on the UK grid.
\end{abstract}

Keywords-frequency control; system inertia; Fast frequency response (FFR); Enhanced frequency response (EFR)

\section{INTRODUCTION}

National Grid is licensed to operate the UK transmission system and is legally required to follow the Security and Quality of Supply Standards (SQSS). The SQSS includes statutory and operational frequency limits. The frequency must be kept within the limits as part of the transmission license obligations. There are certain events which define exceptions for which the frequency is allowed to exceed its limits; (1) Significant Events which are any credible fault such as a single item of power plant or a double line failure, that causes an active power imbalance between $300 \mathrm{MW}$ to $1000 \mathrm{MW}$ where the system frequency shall not deviate by more than $0.5 \mathrm{~Hz}$. (2) Abnormal Events are any credible faults which result in an active power imbalance between $1000 \mathrm{MW}$ to $1320 \mathrm{MW}$ the frequency shall not deviate by more than $0.8 \mathrm{~Hz}$. It is not just frequency magnitude that is an issue, a high rate of change of frequency could trip loss of mains protection on embedded generation exacerbating any frequency issues through loss of generation. Although OfGEM have made some modifications to the Distribution Code and Engineering Recommendation G59, by instructing all new and existing non-synchronous generators of $5 \mathrm{MW}$ or greater to adopt a relay setting of $1 \mathrm{~Hz} / \mathrm{s}$, the settings for smaller generation remain unchanged.

To help control frequency National Grid holds a reserve as part of the operating margin for the power system. There are two types of response, Dynamic and Non-Dynamic. Dynamic response or mandatory frequency response is provided by all generators subject to the grid code requirements which are running and synchronised to the grid. They are acting under governor control and can change their output in response to frequency excursions. This action helps to dampen any oscillations in frequency caused by the disturbances. NonDynamic response is provided by demand/generation selected to trip at low frequency (LF) thresholds. When the trip settings are exceeded then a step change in demand/generation will be introduced to move the frequency in the desired direction. This type of response does not alter output to dampen frequency oscillations and is further split into;

- Decrease in frequency:

- Primary Response is the automatic increase in active power output of a generator or the automatic decrease in demand in response to a fall in system frequency which must be fully available within 10 seconds of the frequency fall and sustainable for a further 20 seconds. Primary response has an approximate 2 second delay in responding to an event [1].

- Secondary Response is the automatic increase in active power output of a generator or the automatic decrease in demand in response to a fall in system frequency which must be fully available within 30 seconds of the frequency fall and sustainable for a further 30 minutes.

- Increase in frequency:

- High Frequency Response is the reduction in active power within 10 seconds after an event and can be sustained indefinitely. It .typically utilises synchronised generators producing active power above their Stable Export Limit (SEL) which are required to reduce active power output in response to an increase in system frequency above the target frequency.

Although these control mechanisms have been used successfully for many years, the system is undergoing transformation with the implementation of the low carbon agenda, which is increasing the amount of renewable generation within the system, which generally has lower inertia. Synchronous generators, which used to make up the majority of generation in the system, store mechanical kinetic 
energy through their inertia. When there is a sudden loss of infeed to the system the system frequency will rapidly fall. This results in synchronous generators decelerating and releasing their stored mechanical kinetic energy arresting the fall in frequency. Alternatively synchronous generators will absorb kinetic energy to slow a frequency increase due to overgeneration [2]. The inertia associated with these generators is therefore key to assisting with frequency response.

The total system inertia isn't directly measured but is calculated by summing the individual inertia of the synchronous generators and turbines that are connected to the power system, which is provided by the generator operator. Demand-side inertia, the inertia associated with users of electricity such as inertia associated with motors rather than generators, must be estimated because it isn't known explicitly. It is estimated by assuming that a percentage of total demand is providing inertia. The total demand is calculated from metering at bulk supply points. Fig 1 shows the calculated system inertia over a day against system demand. As expected, as demand rises there is increasing generation on the system to meet this demand and the estimate of demand inertia increases. System inertia is at a low overnight when system demand is lowest.

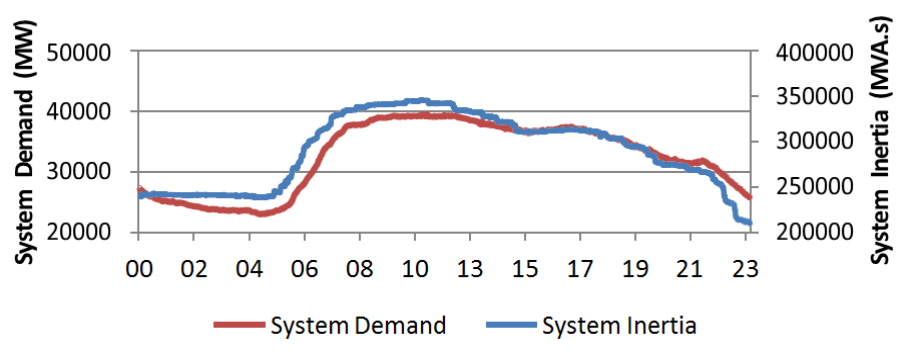

Fig. 1 Calculated system inertia against demand

Fig. 2. Shows the average estimated monthly system demand and inertia over a one year period. The average System inertia is lowest at 240000 MVA.s during July and highest at 300000 MVA.s during February.

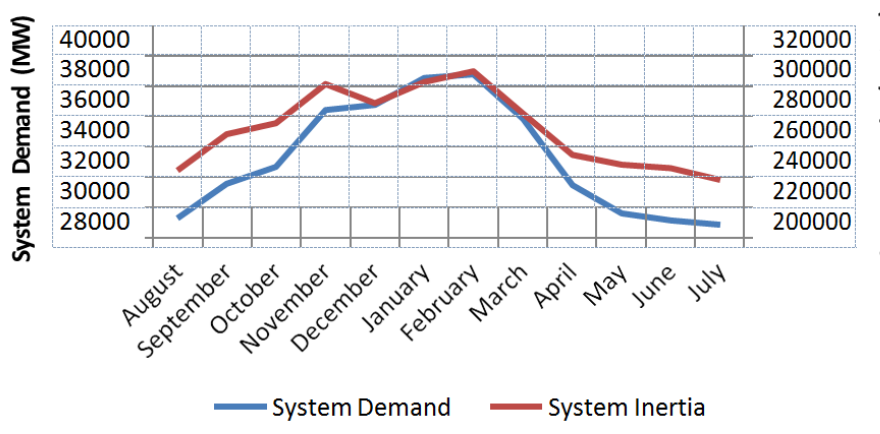

Fig. 2 Calculated average monthly system inertia 2014/15

If system inertia were continue to fall, then utilisation of existing frequency response methods is likely to become more costly as additional frequency response capability is required to compensate for this reduction in inertial response if no other action is taken to adjust the system.

Research in the USA has suggested that faster response services could provide an answer. For example, savings of up to $40 \%$ in reduced procurement have been quoted in California [3]. Faster response offers an additional mechanism to traditional frequency control. Some attempts to incorporate these services based on the efficiency of the fast response and the effective MW on the PJM Energy market have been investigated [4-5]. In the UK, the Enhanced Frequency Control Capability project is an equivalent, research based, Low Carbon Network Funded (LCNF) project being undertaken by National Grid. An aim of the project is to help investigate enhanced frequency control in view of falling system inertia as an alternative to increasing the current availability of current response methods which would be costly. Part of the project will assess different types of frequency response services in hardware order to assess if they would be effective or not. However this project is in early stages and defining the services and putting in place contracts with service providers is proving time consuming.

This paper looks at the response times and ramp rates that would be required from enhanced frequency providers in order to avoid excursions outside of frequency limits in the event of a significant disturbance to the system. The study solves the aggregated inertia differential equation using Euler's method for synchronous generation used in the UK for a variety of system inertial conditions.

Since the system inertia is mostly estimated a statistical approach has been used to look at the effectiveness of the speed of response. Three different scenarios for improving system response have been considered and compared:

1. Primary response with a $2.0 \mathrm{~s}$ detection but looking at faster ramping to full power

2. Rapid response with a $0.5 \mathrm{~s}$ detection

3. Holding more primary response

Although total system inertia is reducing, newer wind generation [6-9], storage [10-11], HVDC systems [12-14] and demand side services [15] with fast response times can all offer a synthetic inertia service. To do this their existing control must be modified so that power output becomes a function of rate of change of frequency and/or a droop type control may also be added to simulate the response of a synchronous machine. However, synthetic inertia is not yet a mandatory function for generator operators and it is difficult to predict and plan for its effect within the existing grid system. Whilst work has been done looking at synthetic inertia for the UK Network [16] which compares the impact of synthetic inertia on ramp rate increase in response - this was for limited grid conditions. The work presented in this paper is similar in background to that in [16] but looks in more detail at ramp rate and response time as an alternative to holding more primary response by considering a more uncertain system inertia rather than a single fixed condition, and for these reasons synthetic inertia has not been included in study.

\section{FREQUENCY MODELLING}

To understand the effect of loss of infeed due to a significant event the method reported in [17] has been used to model frequency: 


$$
\frac{d f}{d t}=\frac{P_{\text {in }}-P_{\text {out }}}{2 S H} f=\frac{\Delta P}{2 I} f
$$

Where

$P_{\text {in }}$ is the active power input to the power system (MW)

$P_{\text {out }}$ is the active power output to the power system (MW)

$\Delta P$ is the active power imbalance (MW)

$\mathrm{S}$ is the apparent power rating of the machines connected to the power system (MVA)

$\mathrm{H}$ is the inertia constant connected to the power system (s)

I is the system Inertia (MVA.s)

$\mathrm{f}$ is the system frequency $(\mathrm{Hz})$

Equation (1) is a differential equation describing the change in frequency with time which can be solved using numerical techniques, in this case Euler's Forward method,

$$
f_{n+1}=\Delta t\left(\frac{\Delta P_{n+1}}{2 I_{n+1}} f_{n}\right)
$$

where $\mathrm{n}$ is the $\mathrm{n}^{\text {th }}$ time-step of width $\Delta \mathrm{t}$.

National Grid calculate system inertia, power imbalance and frequency over a 30 s period and this data was used to validate the model represented by (1) for frequency against time $\mathrm{t}$ as shown in Fig. 3.

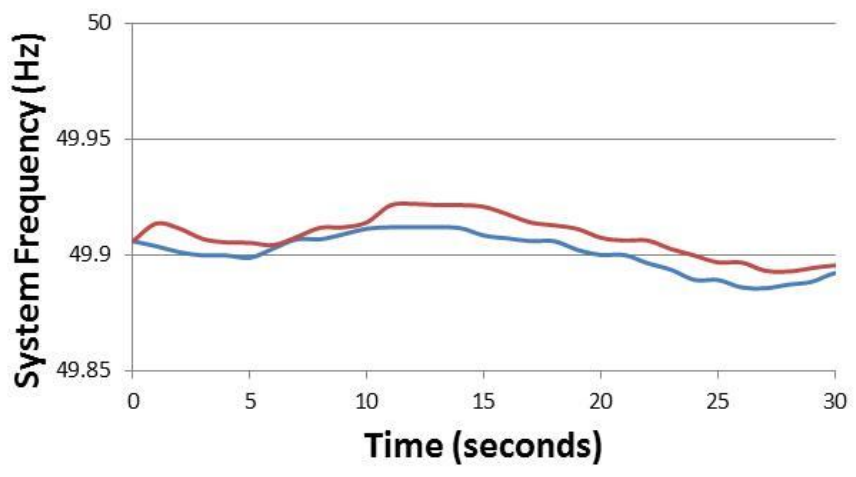

-Measured Frequency —Modelled Frequency

Fig. 3 Comparison of calculated and measured frequency

Fig. 3 shows that the frequency can be estimated within a reasonable degree of accuracy based on a knowledge of inertia I and change in load $\Delta P$, using a $\Delta \mathrm{t}=1 \mathrm{~s}$ time step. The $1 \mathrm{~s}$ is used in this instance because historical data is only available at this level of fidelity. Ideally for a faster transient, data captured at higher frequency would help improve results. This method of analysis can therefore be used to estimate what will happen to the frequency under different load conditions with different system inertia values based on a significant event.

The system model has been simplified when compared to previously published models [16] as the turbine, governor control and demand response is not included. This is because this data is not known with any accuracy, in particular the dynamics of small generating units below 50MW. However, it is felt that this assumption is reasonable for this paper as this will allow the response to be underestimated rather than over estimated erring on the side of caution and the modelling appears to be sufficiently accurate.

The objectives of the simulations are to analyse and evaluate the effectiveness of primary response ramp rate and ramp rate. each of the three scenarios under study described in Section I.

1. Primary response with a $2.0 \mathrm{~s}$ detection but looking at faster ramping to full power

2. Rapid response with a $0.5 \mathrm{~s}$ detection

3. Holding more primary response

The following modelling conditions have been assumed

- A starting frequency of $50 \mathrm{~Hz}$

- An event of a 1000MW interconnector trip

- After the event, $1000 \mathrm{MW}$ of primary response was assumed to activate at different response times and ramp rates as defined in the scenarios

- The new Loss of Mains protection (LOM) relating to Rate of change of Frequency (ROCOF) setting of 0.5 $\mathrm{Hz} / \mathrm{s}$ is active

A scenario will have deemed to fail if the ROCOF is above $0.5 \mathrm{~Hz} / \mathrm{s}$ or the frequency goes below statutory limits for the event.

To undertake the analysis a functional model was used as shown in Fig. 4.

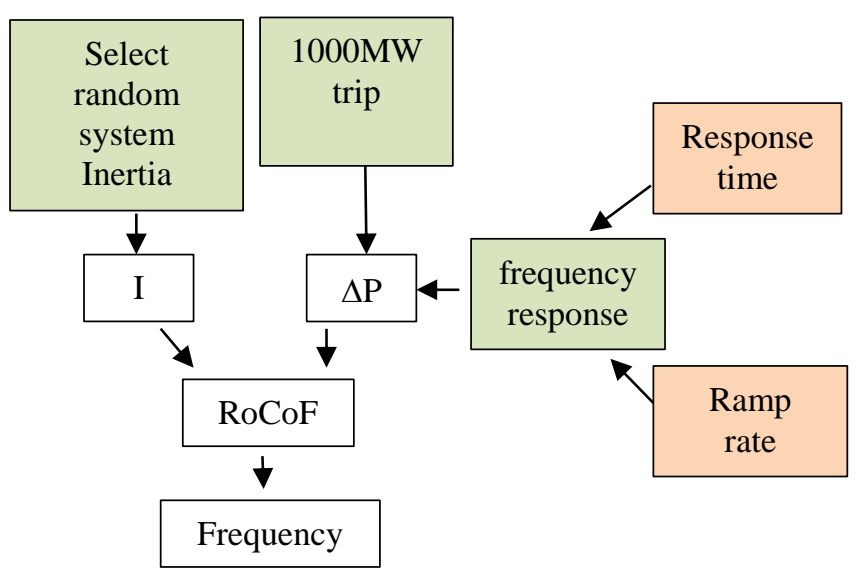

Fig. 4 Functional frequency ramp model

In Figure 4, The frequency is dependent on the value entered into the green box labelled "select random system inertia". Two different methods to estimate this value are used; as a random variable with a maximum and minimum boundary and as a random variable based on a normal distribution of calculated yearlong inertia values. 


\section{PRIMARY RESPONSE WITH FASTER RAMP RATES}

The response of the system is modelled to commence after $2 \mathrm{~s}$ detection period and then linearly ramp to full power after a set period of time. Current practice is that this value is $10 \mathrm{~s}$. However scenario 1 described here looks into the impact of modelling at different ramp rates.

\section{A. Bounded Random Inertia response}

The functional model in Fig. 4 was run 200 times for each ramp rate using a random bounded system inertia. The minimum calculated frequency from (4) was plotted against system inertia as a scatter graph for each ramp rate as shown in Fig. 5.

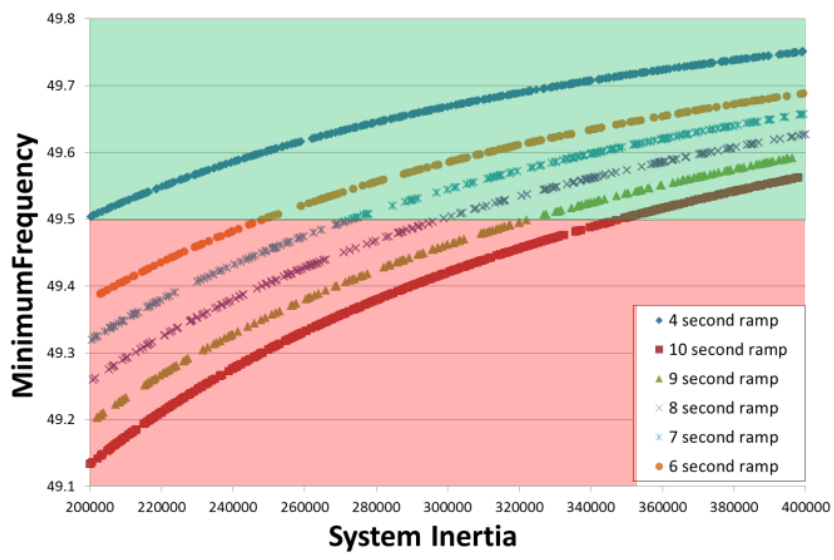

Fig. 5 Minimum frequency against system inertia for different ramp rates

The results were categorised to determine whether the minimum frequency was acceptable. If the minimum frequency was less than 49.5 is would be classed as a "Fail" otherwise it would be a pass. The number of fails was calculated as a percentage of the number of tests to calculate a failure rate for the corresponding ramp rates. The figure above visually represents acceptable frequencies and unacceptable frequencies; the red region is when frequency is less than 49.5. Table I below shows the failure rates.

TABLE I. FAILURE RATES

\begin{tabular}{|c|c|c|c|}
\hline Ramp rate & \multicolumn{1}{|l|}{ Pass } & Fail & Failure rate (\%) \\
\hline 4 & 200 & 0 & 0 \\
\hline 6 & 155 & 45 & 22.5 \\
\hline 7 & 126 & 74 & 37 \\
\hline 8 & 100 & 100 & 50 \\
\hline 9 & 82 & 118 & 59 \\
\hline 10 & 53 & 147 & 73.5 \\
\hline
\end{tabular}

\section{B. Normal distribution based Inertia response}

Fig. 6 shows graphically the deviation of calculated inertia over the course of a year. To help improve the accuracy of the model a normal distribution of inertias based on the mean and standard deviation (270,000 and 54000 respectively) of Fig. 6. Was used as an input to the inertia random number generator to force a better fit, to more representative values of inertia. The simulation was carried out using the different ramp rates and the results are shown in Fig. 7.

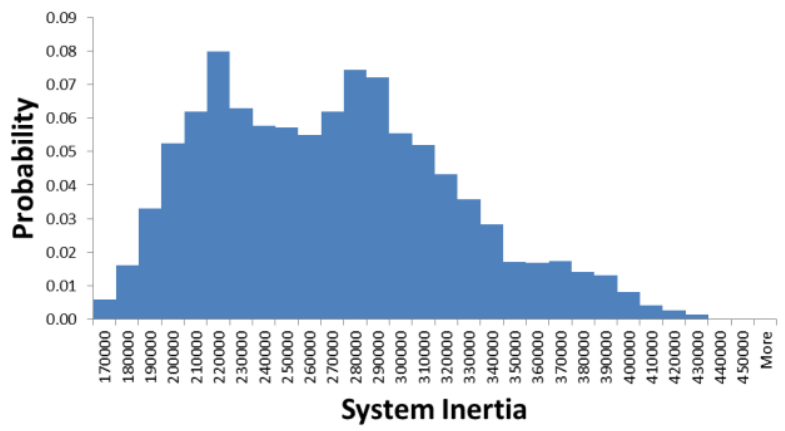

Fig. 6 Calculated system Inertia

Table II shows the equivalent failure rates.

TABLE II. FAILURE RATES

\begin{tabular}{|c|c|c|c|}
\hline Ramp rate & \multicolumn{1}{|l|}{ Pass } & Fail & Failure rate (\%) \\
\hline 4 & 179 & 18 & 9 \\
\hline 6 & 131 & 65 & 33 \\
\hline 7 & 89 & 109 & 55 \\
\hline 8 & 73 & 125 & 63 \\
\hline 9 & 37 & 162 & 81 \\
\hline 10 & 12 & 184 & 94 \\
\hline
\end{tabular}

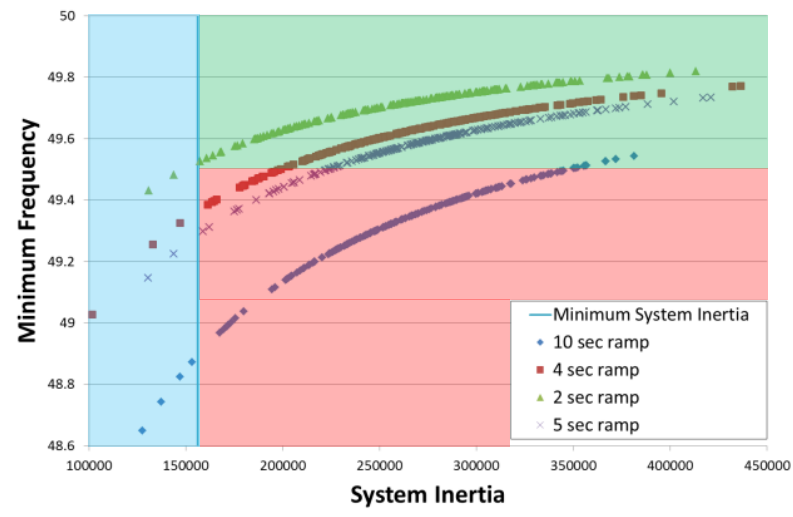

Fig. 7 Minimum frequency against system inertia for different ramp rates

The results from Table II show that as the Inertia through the year is weighted to the lower end the rates of failure between the different means of modelling inertia has worsened to reflect this shift. The majority of results are concentrated around the mean value for system inertia. There are still minimum frequencies recorded below 49.5 even for a 4 second ramp rate because system inertia has been randomized under a different methodology, however a minimum recorded system inertia is used as a benchmark to remove all data below 150000, (minimum calculated from 2015). As system inertia is following a trend that is falling it is theoretically possible that system inertia could reach a value that is even less than the 
low point in 2015 however it is going to be a gradual decline and for the purpose of this paper there isn't any forecast information available to assume a tolerance therefore any value less than the minimum system inertia will be classed as an anomaly. Anything in the pale blue region can be considered an anomalous result. The region that stays within statutory limits is pale green and anything outside statutory limits is pale red. The only ramp rate that remains within statutory limits for all typically calculated inertia values is 2 seconds.

\section{RAPID RESPONSE}

An alternative to a 2 s assumed response time with a fast ramp time is to increase response time. A 5second ramp rate and a $10 \mathrm{~s}$ ramp rate with rapid response of $0.5 \mathrm{~s}$ has been plotted in Fig. 8 along with a 5 second ramp rate and 10 s ramp rate with traditional primary response of 2 s to illustrate the effect that detection time has on minimum frequency using the normally distributed random response based on Fig. 6.

A 5 second ramp rate with primary response had a failure rate of $13 \%$ however if the same response was delivered 0.5 seconds after the trip then the failure rate would be $0 \%$ excluding outliers. Rapid response is effective at holding the frequency within statutory limits even with a ramp time of 5 seconds. For a 10s ramp rate, there was also an improvement in failure rate to nearly half. Table III shows the equivalent failure rates.

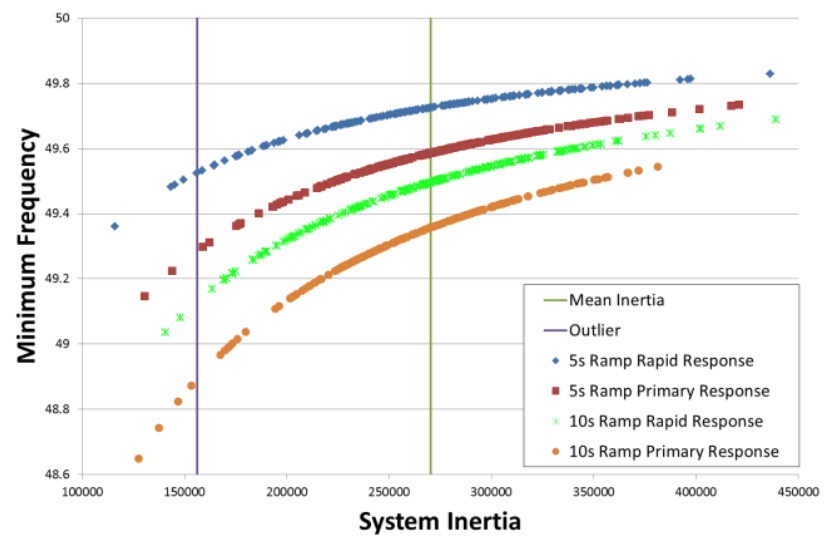

Fig. 8 Minimum frequency against system inertia for different response rates

TABLE III. FAILURE RATES

\begin{tabular}{|c|c|c|c|c|}
\hline $\begin{array}{l}\text { Response } \\
\text { time }\end{array}$ & $\begin{array}{l}\text { Ramp } \\
\text { rate }\end{array}$ & Pass & Fail & Failure rate (\%) \\
\hline $2 \mathrm{~s}$ & $10 \mathrm{~s}$ & 12 & 184 & 94 \\
\hline $2 \mathrm{~s}$ & $7 \mathrm{~s}$ & 89 & 109 & 55 \\
\hline $2 \mathrm{~s}$ & $5 \mathrm{~s}$ & 173 & 25 & 13 \\
\hline $1 \mathrm{~s}$ & $10 \mathrm{~s}$ & 72 & 174 & 63 \\
\hline $1 \mathrm{~s}$ & $7 \mathrm{~s}$ & 163 & 35 & 18 \\
\hline $1 \mathrm{~s}$ & $5 \mathrm{~s}$ & 197 & 2 & 1 \\
\hline $0.5 \mathrm{~s}$ & $10 \mathrm{~s}$ & 95 & 103 & 52 \\
\hline $0.5 \mathrm{~s}$ & $7 \mathrm{~s}$ & 188 & 12 & 6 \\
\hline $0.5 \mathrm{~s}$ & $5 \mathrm{~s}$ & 197 & 0 & 0 \\
\hline
\end{tabular}

In general a reduction in ramp rate and/or response time offers a reduction in failure rate. This can be approximated from Table II and III such that a 1s (or 10\%) improvement in ramp rate offers around $10 \%$ improvement in failure rate, whilst a $0.5 \mathrm{~s}(25 \%)$ improvement in response time gives an improvement of around $15 \%$ in failure rate. Although improving the response time to $0.5 \mathrm{~s}$ offers an improvement in failure rate, the model indicates that with a $10 \mathrm{~s}$ ramp rate there could still be an issue. This indicates that improving response time on its own is not sufficient for guaranteeing frequency response and that a mixture of increasing ramp rate and reducing response time is most feasible for improving the failure rate.

It is interesting to note that values of $7 \mathrm{~s}$ ramp rate with a $1 \mathrm{~s}$ response time have been suggested as potential values within reference [16] however, this paper indicates that this may not be sufficient for all conditions.

\section{HOLDING MORE PRIMARY RESPONSE}

An alternative to changing the response detection or ramp rate is look at holding additional reserve. Fig. 9 the failure rate against primary response for a $5 \mathrm{~s}$ ramp time. The simulations were carried out by increasing the amount of primary response in increments of $100 \mathrm{MW}$.

For each amount of primary response 500 tests were conducted to generate the chart above. It can be seen that as primary response is increased the failure rate exponentially reduces until there is a failure rate of $0 \%$ at $1900 \mathrm{MW}$ of primary response. To achieve a $0 \%$ failure rate with primary response as opposed to rapid response an additional $900 \mathrm{MW}$ of primary response would need to be held with a 5 second ramp rate. It is reasonable to assume that the cost of additional response is at least the same as the rapid response per MW which means that the cost would be at least $90 \%$ higher.

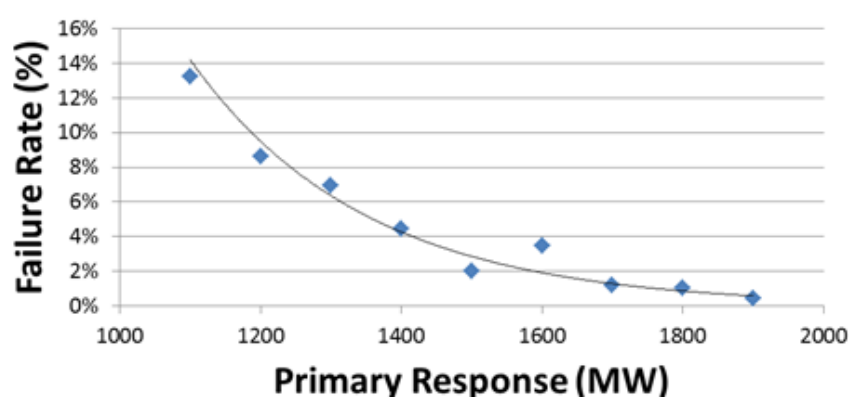

Fig. 9 Failure rate against holding of primary response

Table IV shows the failure rates for different quantities of reserve against a response time of $2 \mathrm{~s}$ for the two different ramp rates; 5 and $10 \mathrm{~s}$. With a $10 \mathrm{~s}$ ramp time around 10 times the amount of frequency is required to minimize the failure rate. This figure is comparable to that is Reference [16]. 
TABLE IV. FAILURE RATES

\begin{tabular}{|c|c|l|c|c|c|}
\hline $\begin{array}{l}\text { Response } \\
\text { time }\end{array}$ & $\begin{array}{l}\text { Ramp } \\
\text { rate }\end{array}$ & $\begin{array}{l}\text { Reserve } \\
\text { Quantity }\end{array}$ & Pass & Fail & $\begin{array}{l}\text { Failure } \\
\text { rate (\%) }\end{array}$ \\
\hline $2 \mathrm{~s}$ & $10 \mathrm{~s}$ & $1000 \mathrm{MW}$ & 12 & 184 & 94 \\
\hline $2 \mathrm{~s}$ & $10 \mathrm{~s}$ & $2000 \mathrm{MW}$ & 395 & 93 & 19 \\
\hline $2 \mathrm{~s}$ & $10 \mathrm{~s}$ & $3000 \mathrm{MW}$ & 465 & 25 & 5 \\
\hline $2 \mathrm{~s}$ & $10 \mathrm{~s}$ & $10,000 \mathrm{MW}$ & 499 & 0 & 0 \\
\hline $2 \mathrm{~s}$ & $5 \mathrm{~s}$ & $1000 \mathrm{MW}$ & 173 & 25 & 13 \\
\hline $2 \mathrm{~s}$ & $5 \mathrm{~s}$ & $2000 \mathrm{MW}$ & 492 & 0 & 0 \\
\hline $2 \mathrm{~s}$ & $5 \mathrm{~s}$ & $3000 \mathrm{MW}$ & 497 & 0 & 0 \\
\hline $2 \mathrm{~s}$ & $5 \mathrm{~s}$ & $10,000 \mathrm{MW}$ & 499 & 0 & 0 \\
\hline
\end{tabular}

\section{CONCLUSIONS}

System inertia is declining which makes frequency more volatile to losses of generation on the system. To explore this further a validated model was created and simulations were carried out to examine the effectiveness of primary response. Primary response is currently the main tool that is used to keep frequency within statutory limits following a loss of system infeed. Three different methods of improving frequency excursions below statutory values were investigated. The simulations show that if the ramp rate was consistently 10 seconds then system frequency is likely to go outside of statutory limits for typical inertia conditions for a trip of 1000 MW. At less than 4 seconds ramp rate response most of the trips were contained except at inertia values that were particularly low which suggests that if the trip were to occur during the day the system would have enough stored energy to keep the frequency within statutory limits even with slightly longer ramp times.

The model was then modified to start ramping generation up at 0.5 seconds which is a realistic response time for rapid response. With a $10 \mathrm{~s}$ ramp rate it is unlikely that with this feasible rate of response that the system can be made more reliable with wholly a change in response time. Therefore to improve the response a combination of both faster response and faster ramp time would be necessary. It can be seen with rapid response that a 5 second ramp rate is sufficient to ensure that frequency stays within statutory limits. Comparing rapid response to primary response with a ramp rate of 5 seconds there is a reduction in failure rate of $13 \%$.

The third scenario studied was to investigate if it was plausible to carry more primary response to be able to maintain statutory limits at higher ramp rates. The problem with holding more response would be the extra expense in to cover the possibility of a trip.

From the simulations it is reasonable to conclude that increasing the rate at which the frequency response ramps up with/and without increasing the speed of response would be most effective for assisting with managing frequency at low inertia values. When synthetic inertia issues are more established this should be included as an additional aid to frequency management.

\section{REFERENCES}

[1] National Grid, "Enhanced Frequency Control Capability (EFCC)," 2014 Accessed online June 2016 https://www.ofgem.gov.uk/publications-and-updates/screeningsubmission-enhanced-frequency-control-capability-efcc-national-gridelectricity-transmission-plc.

[2] J.C.M. Vieira, "Formulas for predicting the dynamic performance of ROCOF relays for embedded generation applications," IEE Proc.-Gener. Transm. Distrib, vol. 153, no. 4, p. 2, 2006.

[3] Y.V. Makarov. J. Ma. S. Lu. T.B. Nguyen , "Assessing the Value of Regulation. Resources Based on Their Time. Response Characteristics.", 2008 available online at http://www.pnl.gov/main/publications/external/technical_reports/PNNL17632.pdf

[4] Ruston Ogburn; Stu Bresler, "Performance-based regulation: Maximizing value through markets", 2012 IEEE Power and Energy Society General Meeting

[5] Xiao, Ying; Su, Qianli; Bresler, Frederick S. Stu; Carroll, Rebecca; Schmitt, Jeffrey R.; Olaleye, Michael "Performance-based regulation model in PJM wholesale markets", PES General Meeting | Conference \& Exposition, 2014 IEEE, On page(s): $1-5$

[6] Francisco M. Gonzalez-Longatt , "Activation schemes of synthetic inertia controller for full converter wind turbine generators",PowerTech, 2015 IEEE Eindhoven

[7] Francisco M. Gonzalez-Longatt, "Effects of the synthetic inertia from wind power on the total system inertia: simulation study", Environment Friendly Energies and Applications (EFEA), 2012 2nd International Symposium on

[8] Fei Teng; Goran Strbac, "Assessment of the Role and Value of Frequency Response Support From Wind Plants",IEEE Transactions on Sustainable Energy, Year: 2016, Volume: 7, Issue: 2,Pages: 586 - 595

[9] Lei Wu; David Infield, "Power system frequency management challenges - a new approach to assessing the potential of wind capacity to aid system frequency stability", IET Renewable Power Generation, Year: 2014, Volume: 8, Issue: 7, Pages: 733 - 739

[10] Olivier Mégel; Johanna L. Mathieu; Göran Andersson, "Maximizing the potential of energy storage to provide fast frequency control", IEEE PES ISGT Europe 2013, Pages: 1 - 5

[11] Xinran Li; Yawei Huang; Jiyuan Huang; Shaojie Tan; Ming Wang; Tingting Xu; Xingting Cheng, " Modeling and control strategy of battery energy storage system for primary frequency regulation”,Power System Technology (POWERCON), 2014, Pages: 543 - 549

[12] X. Liu, A. Lindemann, and N. Wirtz, "Generator emulation control for providing synthetic inertia in VSC-HVDC system," in Proc. International",Wind Engineering Conference, Hannover, Germany, Sep. 2014.

[13] M. Yu, A. Dysko, C. D. Booth, A. J. Roscoe, and J. Zhu, "A review of control methods for providing frequency response in VSC-HVDC transmission systems," in Power Engineering Conference (UPEC), 2014

[14] J. Zhu, C. D. Booth, G. P. Adam, A. J. Roscoe, and C. G. Bright, "Inertiaemulation control strategy for VSC-HVDC transmission systems," IEEE Transactions on Power Systems, vol. 28, no. 2, pp. 1277-1287, 2013

[15] Vincenzo Trovato; Simon H. Tindemans; Goran Strbac, "Demand response contribution to effective inertia for system security in the GB 2020 gone green scenario",IEEE PES ISGT Europe 2013

[16] William Murrell; Li Ran; Jihong Wang, "Modelling UK power system frequency response with increasing wind penetration",2014 IEEE Innovative Smart Grid Technologies - Asia (ISGT ASIA), Pages: 1 - 6

[17] San Joaquin Delta College, "Calculus Lab," n.d.. [Online]. Accessed June 1016 Available: http://calculuslab.deltacollege.edu/ODE/7-C-1/7-C-1-hc.html. 